Portland State University

PDXScholar

Summer 2021

\title{
Optimization of 3D Printed Mold Performance for Injection Molding via Hollow Infill Patterns
}

Alan Fong

Portland State University

Follow this and additional works at: https://pdxscholar.library.pdx.edu/honorstheses

Part of the Other Materials Science and Engineering Commons, and the Other Mechanical Engineering Commons

Let us know how access to this document benefits you.

\section{Recommended Citation}

Fong, Alan, "Optimization of 3D Printed Mold Performance for Injection Molding via Hollow Infill Patterns" (2021). University Honors Theses. Paper 1132.

https://doi.org/10.15760/honors.1163

This Thesis is brought to you for free and open access. It has been accepted for inclusion in University Honors Theses by an authorized administrator of PDXScholar. Please contact us if we can make this document more accessible: pdxscholar@pdx.edu. 
Optimization of 3D Printed Mold Performance for Injection Molding via Hollow Infill Patterns

\author{
by \\ Alan Fong \\ An undergraduate honors thesis submitted in partial fulfillment of the \\ requirements for the degree of \\ Bachelor of Science \\ in \\ University Honors \\ and \\ Mechanical Engineering
}

Thesis Adviser

Faryar Etesami

Portland State University

2021 


\title{
Optimization of 3D Printed Mold Performance for Injection Molding via Hollow Infill Patterns
}

\author{
Alan Fong, Faryar Etesami \\ ME Department, Portland State University
}

\begin{abstract}
:
The applicability of hollow infill patterns has been explored for its applications in making 3D printed polymer-based injection molds in the additive manufacturing industry. Hollow infill patterns offer a significant reduction in material costs as well as the opportunity for reducing the cooling times via pumping a coolant fluid through the hollow cavity in a similar fashion to traditional conformal cooling channels. A 3D Jacks Support Hollow mold model was determined to be the best performing design. FEA analysis was conducted to determine the maximum reduction in internal volume (percentage of material saved) that could be achieved without exceeding the acceptable stress and deflection limitations for the 3D Jacks Supports Hollow mold design compared to the traditional base solid mold model used in injection molding. The transient thermal simulations were performed to determine the effects of cooldown times between the base solid mold model and the hollow 3D Jacks Supports model. Finally, real flow (transient conjugate heat transfer) simulation was performed in order to determine a more accurate result pertaining to the cooldown time for the best performing polymer in this study (30\% carbon reinforced PEEK). The results show a 62\% in material saved for reinforced PEEK compared to the base solid mold and a cooling time reduction of $93.9 \%$. A transient conjugate heat transfer flow analysis indicates a $27 \%$ difference between results when compared to a simplified transient thermal analysis.
\end{abstract}

\section{Introduction:}

The process of plastic injection molding [1], [2] involves the heating of plastic material up to the point where it becomes soft enough to be forced through a closed mold cavity. Once the plastic has been sufficiently cooled and hardened, the finished part is then ejected from the cavity. Traditionally, the mold is made of metals such as steel and aluminum due to their inherent mechanical/thermal properties which can withstand the high temperature and pressure that the mold is subjected to during this process. Generally, the manufacturing of these metal molds is accomplished via subtractive manufacturing techniques such as machining, whereby a solid piece of raw material is removed through a controlled process (drilling, CNC milling, etc.) until the desired geometry is made. Unfortunately, subtractive manufacturing is a costly and timeconsuming process due to the fact that depending on the kind of geometry desired, all of the material that is required to be removed in order to obtain the complex shape via machining is a traditionally expensive process. 
The advantages of additive manufacturing are primarily based on the principle that this process involves adding and joining together raw material on a layer-by-layer basis to form a part [3]. As a result, the part is made with the exact amount of material necessary to produce it and the technology also allows for complex/detailed geometric designs to be produced quickly with ease. This allows for a more cost-effective and time-saving approach (compared to traditional subtractive manufacturing) that could be applied to the manufacturing of molds for plastic injection molding. With the increased adoption of additive manufacturing, the improvement in 3D printing technology has allowed for a wide array of material choices ranging from metals (steel and aluminum) to polymers (plastics), composites, and resins [4]. Additionally, the viability of additive manufacturing has been researched on the production of sand molds for metal casting [5], [6] as well as investment casting for light metals [7].

However, in spite of the apparent advantages of additive manufacturing compared to traditional subtractive manufacturing, there are still many issues that need to be addressed in regards to the design and manufacturing problems that may occur during the production of 3D printed molds for plastic injection molding [8]. This paper seeks to provide simulation-based solutions to two primary issues which involves the reduction of the time/cost it takes to manufacture (3D print) molds by minimizing the volume of material that needs to be printed without critically affecting the structural rigidity of the mold. The other issue is in regard to the inherently slow heat transfer characteristics of polymer molds which increases the cooling time needed for solidification and could potentially worsen the mechanical properties of the mold due to prolonged exposure to high temperatures/pressure. A potential design approach that could address these two problems is the implementation of a hollowed-out (shell) mold geometry in which the internal cavity of the mold is comprised of infill patterns that provide structural support while subjected to molding pressure. This allows a significant decrease in material usage due to the decreased volume of the mold without compromising its strength, while also reducing the time and cost required to manufacture it. A hollow infill pattern design additionally allows for the usage of a cooling liquid to pass through it in a similar fashion to traditional conformal cooling channels [9]-[13] and may even surpass the performance improvements obtained from these conventional channels. In this simulation-focused study, a comparison was made between the material saving (volume of material reduced) and cooling time reduction across different hollow 3D printed mold designs for a $25 \mathrm{~mm}$ spherical lens that is to be injection molded out of HDPE. The results obtained from these simulations are then compared to a baseline solid mold in terms of their mechanical and thermal performance.

\section{Mold Materials and Designs:}

The materials used for the purposes of this study were Aluminum 6061 for the metal and Polyether Ether Ketone (PEEK) for the thermoplastic due to its excellent mechanical properties when subjected to high temperatures [14]. Additionally, a 30\% carbon-reinforced PEEK was used in this study as this version provided even greater mechanical and heat transfer properties 
compared to the unreinforced counterpart. The thermal and mechanical properties of PEEK, $30 \%$ reinforced PEEK, and Aluminum 6061 are listed in Table-1 below:

Table 1 - Properties of materials used for mold modeling simulation (FEA, Transient thermal, and Transient Conjugate Heat Transfer flow analysis)

\begin{tabular}{|c|c|c|c|c|c|c|}
\hline Material & $\begin{array}{c}\text { Melting } \\
\text { Point }\left({ }^{\circ} \mathrm{C}\right)\end{array}$ & $\begin{array}{c}\text { Yield } \\
\text { strength } \\
\text { (MPa) }\end{array}$ & $\begin{array}{l}\text { Ultimate } \\
\text { tensile } \\
\text { strength } \\
\text { (MPa) }\end{array}$ & $\begin{array}{c}\text { Young } \\
\text { Modulus of } \\
\text { elasticity } \\
\text { (GPa) }\end{array}$ & $\begin{array}{c}\text { Poisson's } \\
\text { Ratio }\end{array}$ & $\begin{array}{c}\text { Thermal } \\
\text { conductivity } \\
\left(\mathrm{W} / \mathrm{m}^{\circ} \mathrm{C}\right)\end{array}$ \\
\hline PEEK & 332 & 90 & 96.3 & 3.85 & 0.4 & 0.32 \\
\hline $\begin{array}{c}\text { PEEK 30\% } \\
\text { Carbon filled } \\
\text { (AKROTEK } \\
\circledR)\end{array}$ & 386 & - & 245 & 6.40 & 0.4 & 0.95 \\
\hline $\begin{array}{c}\text { Aluminum } \\
6061\end{array}$ & 600 & 276 & 310 & 71 & 0.33 & $\begin{array}{c}155-165 \\
\text { at } 50{ }^{\circ} \mathrm{C}-100 \\
{ }^{\circ} \mathrm{C}\end{array}$ \\
\hline
\end{tabular}

The design of the mold used in this study is for a $25 \mathrm{~mm}$ diameter spherical lens that is made of high-density polyethylene (HDPE). HDPE has a melting point that generally ranges anywhere between 130-160 degrees Celsius. The dimensions of this baseline (solid) traditional mold has a length of $112 \mathrm{~mm}$ and a width of $60 \mathrm{~mm}$. The thickness of the mold is $15 \mathrm{~mm}$ with a $10 \mathrm{~mm}$ fillet edges across each corner. A SolidWorks model of the HDPE lens mold is shown below in Figure-1:

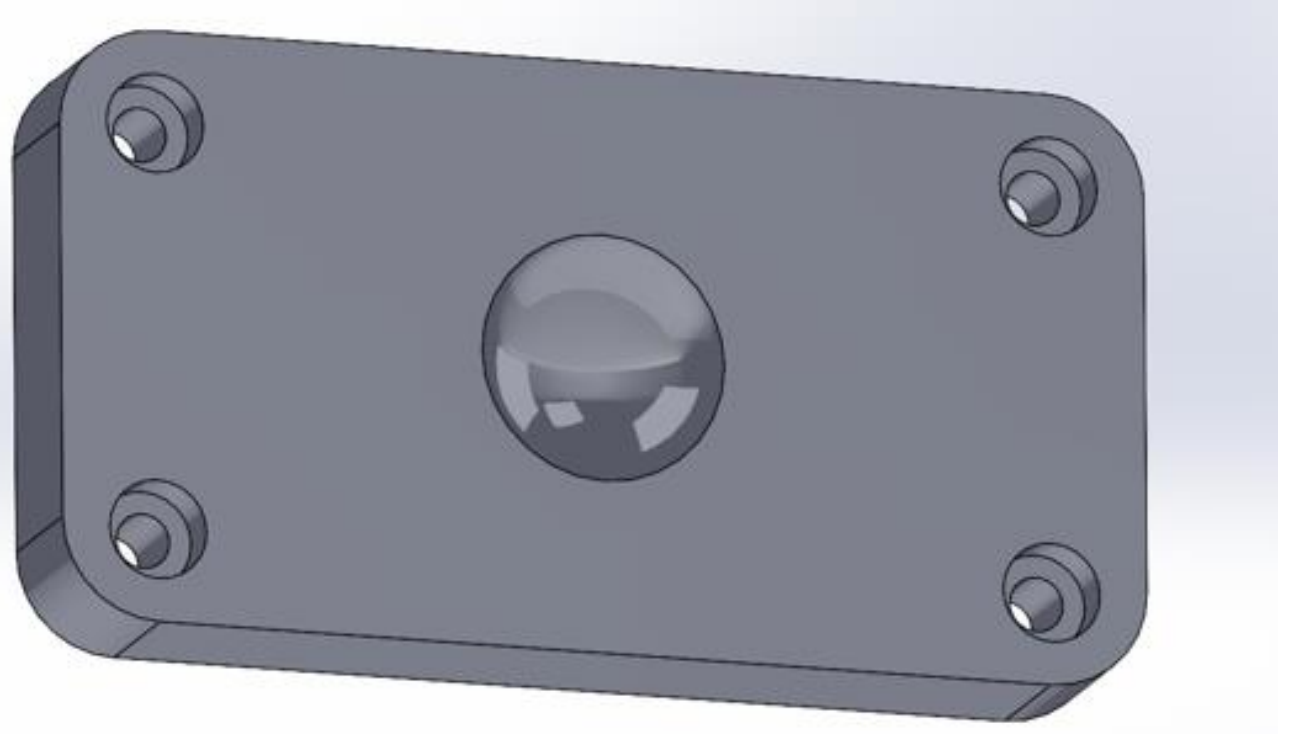

Figure 1 - Base solid model of HDPE lens injection mold with a $25 \mathrm{~mm}$ hemisphere (two identical halves of this model makes up the mold) 
Polyether Ether Ketone (PEEK) was chosen as the thermoplastic to be used in this study due to its outstanding thermo and mechanical properties as well as its applications in Fused Filament Fabrication (FFF) 3D printing technology, which is a commonly used technology in the industry for a number of applications ranging from medical, automotive, aerospace, etc... as well as at even the consumer level (hobby 3D printers). PEEK's ability to maintain structural rigidity and therefore prevent significant deformation at elevated temperatures of over 300 degrees Celsius makes it an excellent material for use in injection molding applications. For the purposes of this simulation-based study, an injection pressure of $20 \mathrm{MPa}$ was determined to be sufficient for the size of the $25 \mathrm{~mm}$ HDPE lens mold. This pressure is used across all of the mold designs (both solid and hollow geometries) and each of the materials (Aluminum 6061, PEEK, and 30\% Carbon-reinforced PEEK).

\section{Hollow Mold Designs:}

Initially, the performance of five different hollow mold designs were explored in a previous study conducted by Dr. Yasser Alizadeh and Dr. Faryar Etesami from the Mechanical \& Materials Engineering Department at Portland State University, which consists of the following:

Hollow Horizontal Pipes Mold: The design involves implementing round $2.8 \mathrm{~mm}$ cylindrical shaped voids extruded across the length of the mold.

Hollow Horizontal Walls Mold: The design involves implementing rectangular voids extruded across the length of the mold.

Hollow Vertical Pipes Mold: The design involves implementing round $2.8 \mathrm{~mm}$ pipe shaped voids extending along the thickness of the mold.

Hollow Vertical Honeycomb Cells Mold: The design involves implementing hexagonal shaped voids (6-sided/ $3 \mathrm{~mm}$ walls) extending along the thickness of the mold.

Jack Supports Pattern (JSP) Hollow Mold: The design involves implementing orthogonal cylindrical bars that extend across the length and thickness of the mold. The diameter of the pillars and the density of the pillars (number of pillars and spacing between each) were adjusted as the design parameters until the design constraints were finally met.

For each of these hollow mold designs, an offset thickness of $2 \mathrm{~mm}$ was used as the "shell" for the base of the mold and the internal cavity was filled by these geometric structures. Ultimately, the 3D Jacks Supports Pattern design (shown in Figure-2) was determined to be the best performer out of the other designs as it was able to meet the stress and deformation constraints while saving the most material (52\% internal volume reduction). As such, for the purposes of this study, the 3D Jacks Supports hollow design will be used for FEA, Transient Thermal, and Conjugate Heat Transfer (flow simulation) analysis. 


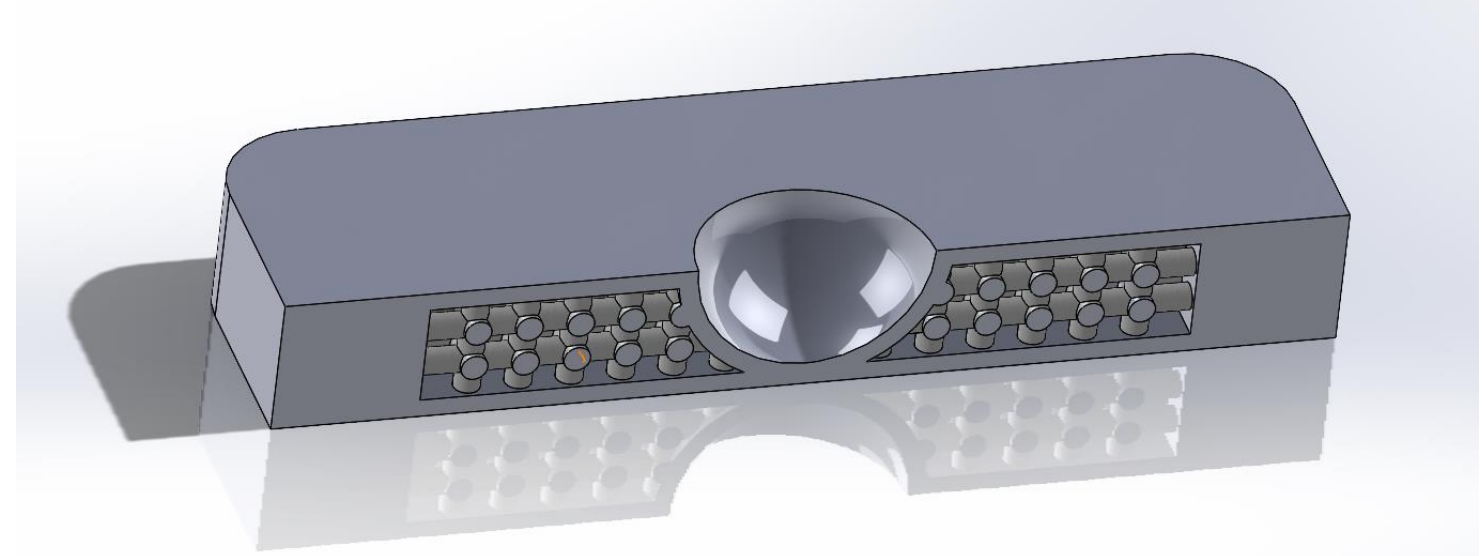

Figure 2 - Cross-sectional view of hollow HDPE lens mold with internal 3D Jacks Support geometry (orthogonal $2.8 \mathrm{~mm}$ cylindrical pillars intersecting along all three axes)

\section{Finite Element Analysis (FEA for stress and deformation):}

An injection molding pressure of $20 \mathrm{MPa}$ was applied to the surface of the spherical mold cavity for each of the designs. The FEA (stress and deformation) simulations were performed via SolidWorks CAD software. Due to the simplistic geometry of the structure for the base HDPE lens mold, a standard mesh parameter was determined to yield accurate results. The global size (average size of each element) was set to $4.00 \mathrm{~mm}$ with a tolerance of $0.20 \mathrm{~mm}$ (whereby adjacent nodes within this set distance would be merged together in order to mitigate issues during mesh generation). For the purposes of this study, the yield strength of PEEK was set to $100 \mathrm{MPa}$. For the 3D Jacks Supports Hollow mold design, the internal volume was reduced iteratively until the maximum von Mises stress experienced by the mold cavity reach $80 \%$ of the mold material's yield strength (which in the case would be $80 \mathrm{MPa}$ ). Figure-3 below portrays the maximum von Mises stress and Figure-4 shows the total deformation experienced by the base solid model for the HDPE lens mold:

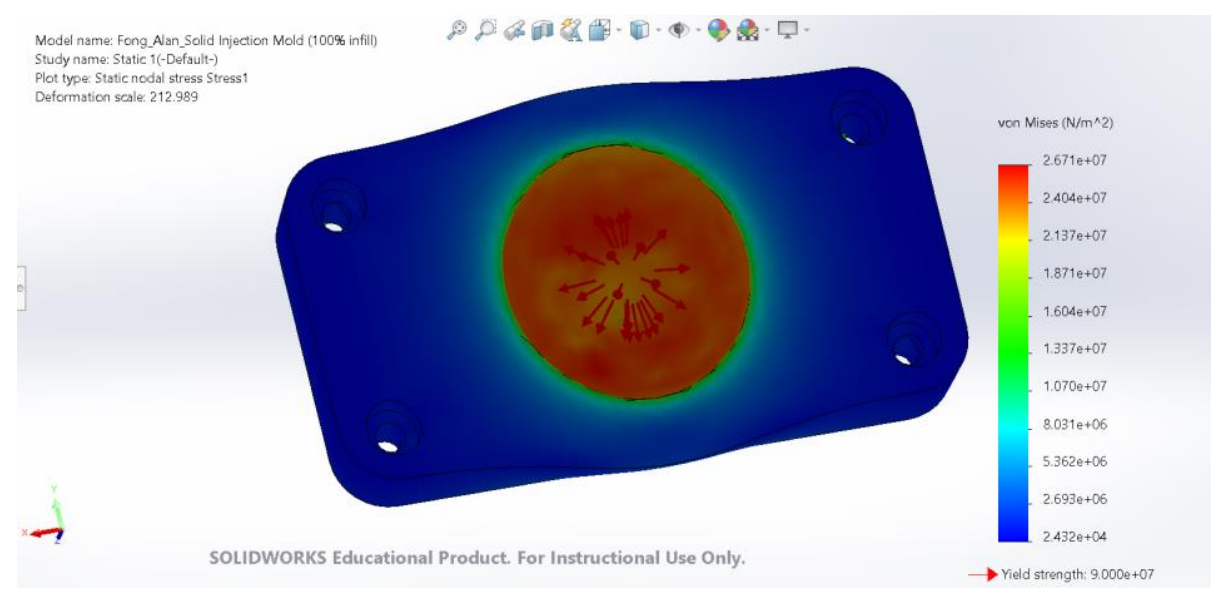

Figure 3 - Maximum von Mises stress experienced by the solid base model in $\mathbf{N} / \mathbf{m}^{\wedge} \mathbf{2}$ 


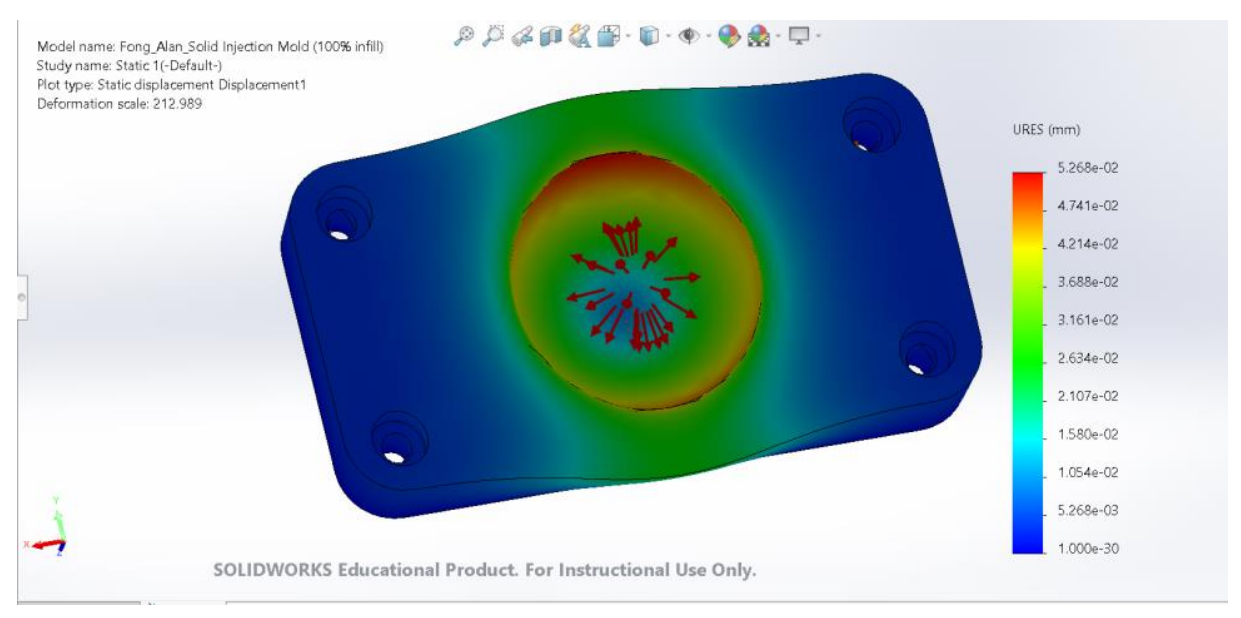

Figure 4 - Maximum deformation experienced by the solid base model in $\mathbf{m m}$.

The maximum von Mises stress on the surface of the hemisphere mold cavity was determined to be 26.71 MPa which is well below the acceptable stress limit of $80 \mathrm{MPa}$. The maximum deformation when subjected to the $20 \mathrm{MPa}$ molding pressure was determined to be $0.053 \mathrm{~mm}$ which is also within the acceptable displacement limit of $0.1 \mathrm{~mm}$.

\section{Transient Thermal Analysis:}

For the purposes of this simulation study, a molding temperature of 100 degrees Celsius was used for the HDPE lens and as such, it was set as the initial temperature of the mold.

Subsequently, an ejection temperature of 50 degrees Celsius was set as the target temperature for determining the cooling time between each mold design. As discussed earlier, reducing cooldown times for polymer-based materials is often a significant challenge due to their inherently poor thermal conductivity characteristics compared to metals which have a significantly greater thermal conductivity that makes them excellent/efficient thermal conductors. Therefore, in this study the 3D Jacks Supports Hollow mold model with PEEK material was simulated for purpose of determining the potential reduction in cooldown time compared to the traditional solid mold design. The thermal conductivity of the Aluminum 6061 was set to $167 \mathrm{~W} / \mathrm{m} .{ }^{\circ} \mathrm{C}$ and the thermal conductivity of the PEEK was set to a $0.25 \mathrm{~W} / \mathrm{m}$. ${ }^{\circ} \mathrm{C}$. An ambient constant temperature of $20{ }^{\circ} \mathrm{C}$ was used for simulating water flowing through the hollow 3D Jacks Supports mold as a liquid coolant in a similar manner to conventional conformal cooling channels. As such, the convection coefficient of water was set to a value of $3,000 \mathrm{~W} / \mathrm{m}^{2}$. ${ }^{\circ} \mathrm{C}$ (assuming forced convection).

\section{Flow Simulation Analysis:}

Due to the complexity of the 3D Jacks Supports structure within the hollow mold design, it was determined that a real flow simulation performed in SolidWorks CAD software was necessary to produce more accurate results for the cooldown time associated with the $30 \%$ carbon-reinforced PEEK with the 3D Jacks design (due to the uniform temperature distribution of the transient thermal analysis which assumes that the water flows without inhibition across the dense internal 
mold geometry). In order to simulate the flow of fluid within the hollow mold volume, two inlets and outlets were designed across opposite lengths of the 3D Jacks Supports mold as shown in Figure-5 below:

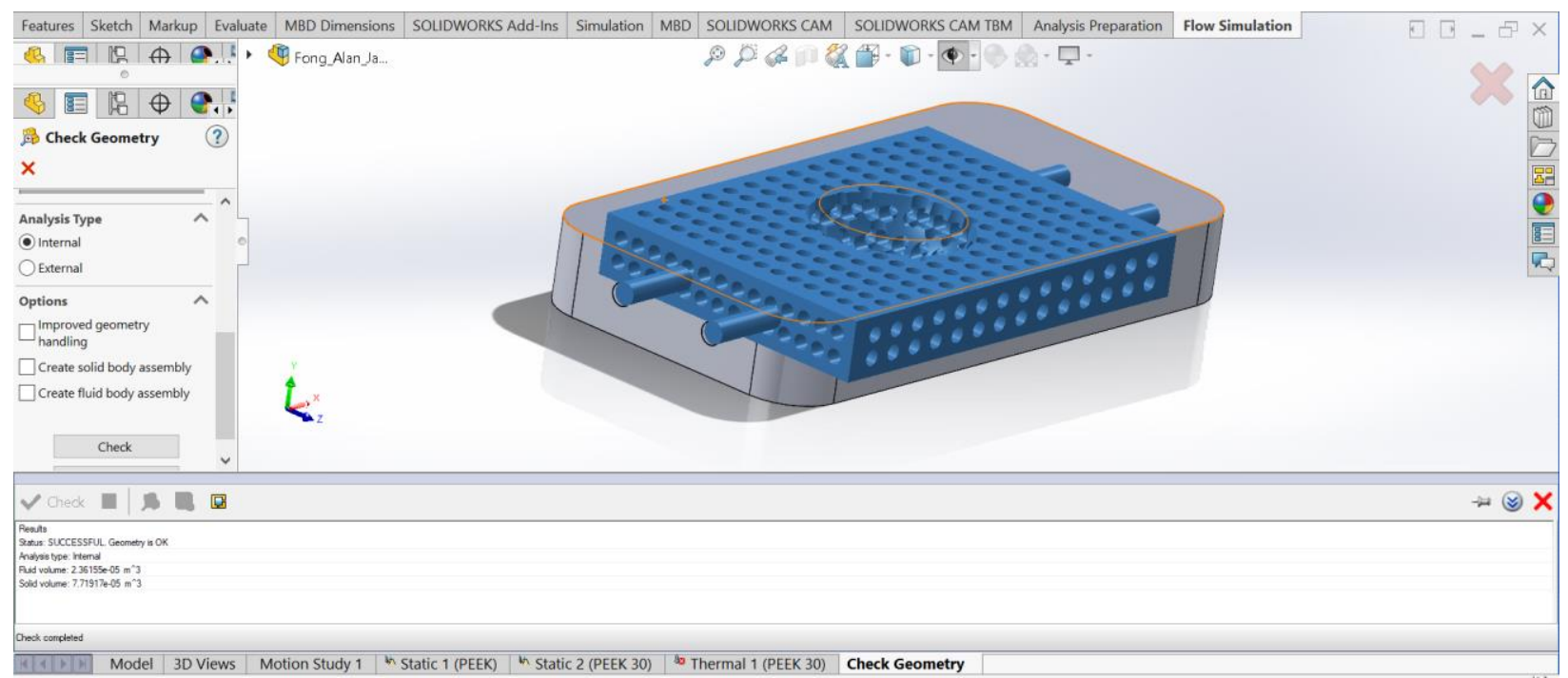

Figure 5 - Internal volume of the 3D Jacks Supports mold highlighted in blue with two inlets and two outlets for the coolant fluid (water) to flow through

The analysis type for this flow simulation was set to "internal" with physical features set to "heat conduction in solids" and "time-dependent" as this is a transient conjugate heat transfer scenario (where the $30 \%$ reinforced PEEK mold is initially hot at $100{ }^{\circ} \mathrm{C}$ and cooled by a fluid flowing through). The fluid type was selected to be a liquid with a default fluid of water as the coolant. Subsequently, for the purposes of this study, an assumption was made to include both laminar and turbulent flow for the flow characteristic of this simulation. The inclusion of both laminar and turbulent flow was determined to best portray the flow of water as it initially enters the uniform cylindrical shape of the two inlets and the expected turbulent flow that occurs as fluid maneuvers across the dense geometry of the 3D Jacks Supports structures. The inlet mass flowrate for the water coolant was set to $0.0005 \mathrm{~kg} / \mathrm{s}$. The initial solid temperature was set to 100 ${ }^{\circ} \mathrm{C}$ (molding temperature) and temperature of the fluid was set to a constant value of $20{ }^{\circ} \mathrm{C}$ (coolant temperature).

\section{Results/Discussion:}

The FEA simulations were performed to determine the maximum reduction in internal volume (percentage of material saved) that could be achieved without exceeding the acceptable tensile stress and deflection limitations for the 3D Jacks Supports Hollow mold design compared to the traditional base solid mold model used in injection molding. The maximum stress and deformation for the base solid model and 3D Jacks Supports model are summarized below in Table-2: 
Table 2 - Performance metrics comparison between the base solid mold vs. the 3D Jacks Supports across each material

\begin{tabular}{|c|c|c|c|c|}
\hline Design & Material & $\begin{array}{l}\text { Material } \\
\text { saved }\end{array}$ & $\begin{array}{l}\text { Max von } \\
\text { Mises (MPa) }\end{array}$ & $\begin{array}{l}\text { Max } \\
\text { Deformation } \\
(\mathrm{mm})\end{array}$ \\
\hline \multirow[t]{3}{*}{ SOLID MOLD } & $\begin{array}{l}\text { Aluminum } \\
6061\end{array}$ & $0 \%$ & 27.22 & 0.0027 \\
\hline & PEEK & $0 \%$ & 26.71 & 0.0530 \\
\hline & $\begin{array}{l}\text { Reinforced } \\
\text { PEEK (30) }\end{array}$ & $0 \%$ & 26.72 & 0.0320 \\
\hline \multirow{3}{*}{$\begin{array}{l}\text { 3D JACKS } \\
\text { SUPPORTS } \\
\text { (hollow) }\end{array}$} & $\begin{array}{l}\text { Aluminum } \\
6061\end{array}$ & $65 \%$ & 78.76 & 0.0057 \\
\hline & PEEK & $51 \%$ & 75.29 & 0.0990 \\
\hline & $\begin{array}{l}\text { Reinforced } \\
\text { PEEK }\end{array}$ & $62 \%$ & 75.29 & 0.0590 \\
\hline
\end{tabular}

According to Table-2, the results show that between a traditional solid mold design and a hollow 3D Jacks Supports mold, there is a volume reduction of over 50\% across each of the materials while still remaining within the acceptable tensile stress of $80 \mathrm{MPa}$ and allowable deformation of $0.1 \mathrm{~mm}$. While the PEEK hollow mold design provided $51 \%$ in material savings, the carbon reinforced PEEK yielded $62 \%$ in material savings with only a $3 \%$ difference from the best performing Aluminum 6061 material as a result of its superior thermal conductivity which is to be expected from metals.

The transient thermal simulations were performed to determine the effects of cooldown times between the base solid mold model and the hollow 3D Jacks Supports model. As described earlier, the internal surfaces within the hollow 3D Jacks model were set as convective surfaces in contact with water which was set at a constant $20^{\circ} \mathrm{C}$ with a convection coefficient of 3,000 $\mathrm{W} / \mathrm{m}^{2} \cdot{ }^{\circ} \mathrm{C}$. The thermal conductivity of PEEK was set to $0.25 \mathrm{~W} / \mathrm{m}$. ${ }^{\circ} \mathrm{C}$ and $0.95 \mathrm{~W} / \mathrm{m}$. ${ }^{\circ} \mathrm{C}$ for the $30 \%$ carbon reinforced PEEK. The initial molding temperature was set to $100^{\circ} \mathrm{C}$ and the suitable ejection temperature for the HDPE lens mold was set to $50{ }^{\circ} \mathrm{C}$. The cooldown times for both the base solid model and 3D Jacks Supports model are summarized below in Table-3: 
Table 3 - Transient thermal cooling comparison between the base solid mold vs. the 3D Jacks Supports across each material

\begin{tabular}{|l|l|c|}
\hline \multicolumn{1}{|c|}{ Design } & \multicolumn{1}{|c|}{ Material } & $\begin{array}{l}\text { Cooling time from } \\
100^{\circ} \mathrm{C} \text { to } 50^{\circ} \mathrm{C} \text { in } \\
\text { seconds }\end{array}$ \\
\hline SOLID MOLD & Aluminum 6061 & \multicolumn{1}{|c|}{11.56} \\
\hline & PEEK & 843 \\
\hline & $\begin{array}{l}\text { Reinforced } \\
\text { PEEK (30) }\end{array}$ & 478 \\
\hline 3D JACKS SUPPORTS & Aluminum 6061 & 1.18 \\
\hline (hollow) & PEEK & 88.2 \\
\hline & Reinforced PEEK & 29.1 \\
\hline
\end{tabular}

According to Table-3, it is no surprise that Aluminum 6061 once again takes the lead in yielding the shortest cooldown time of 11.56 seconds for the solid mold and 1.18 seconds for the 3D Jacks Supports model. However, it is important to note the significant cooldown time reduction between the solid (843 seconds) and hollow PEEK (88.2 seconds) mold models which resulted in an $89.5 \%$ cooling time reduction. Comparatively, the cooldown time reduction is even greater between the solid and hollow 30\% carbon reinforced PEEK mold models which had a 93.9\% cooling time reduction.

Finally, a real flow (transient conjugate heat transfer) simulation was performed in order to determine a more accurate result pertaining to the cooldown time for the best performing polymer in this study (30\% carbon reinforced PEEK) due to the ununiform flow characteristics that are to be expected when the water coolant passes through the dense geometry of the internal structure from the hollow 3D Jacks Supports mold design. To properly simulate these conditions, an assumption was made to include both laminar and turbulent flow characteristics. The initial temperature of the mold was set to $100{ }^{\circ} \mathrm{C}$ (molding temperature) and the temperature of the cooling fluid (water) was set to a constant $20^{\circ} \mathrm{C}$. The inlet mass flowrate for the water coolant was set to $0.0005 \mathrm{~kg} / \mathrm{s}$. A plot of the center of the mold cavity temperature as a function of time as the $3 \mathrm{D}$ Jacks Supports model is cooled from $100{ }^{\circ} \mathrm{C}$ to $50{ }^{\circ} \mathrm{C}$ is shown in Figure- 6 below: 


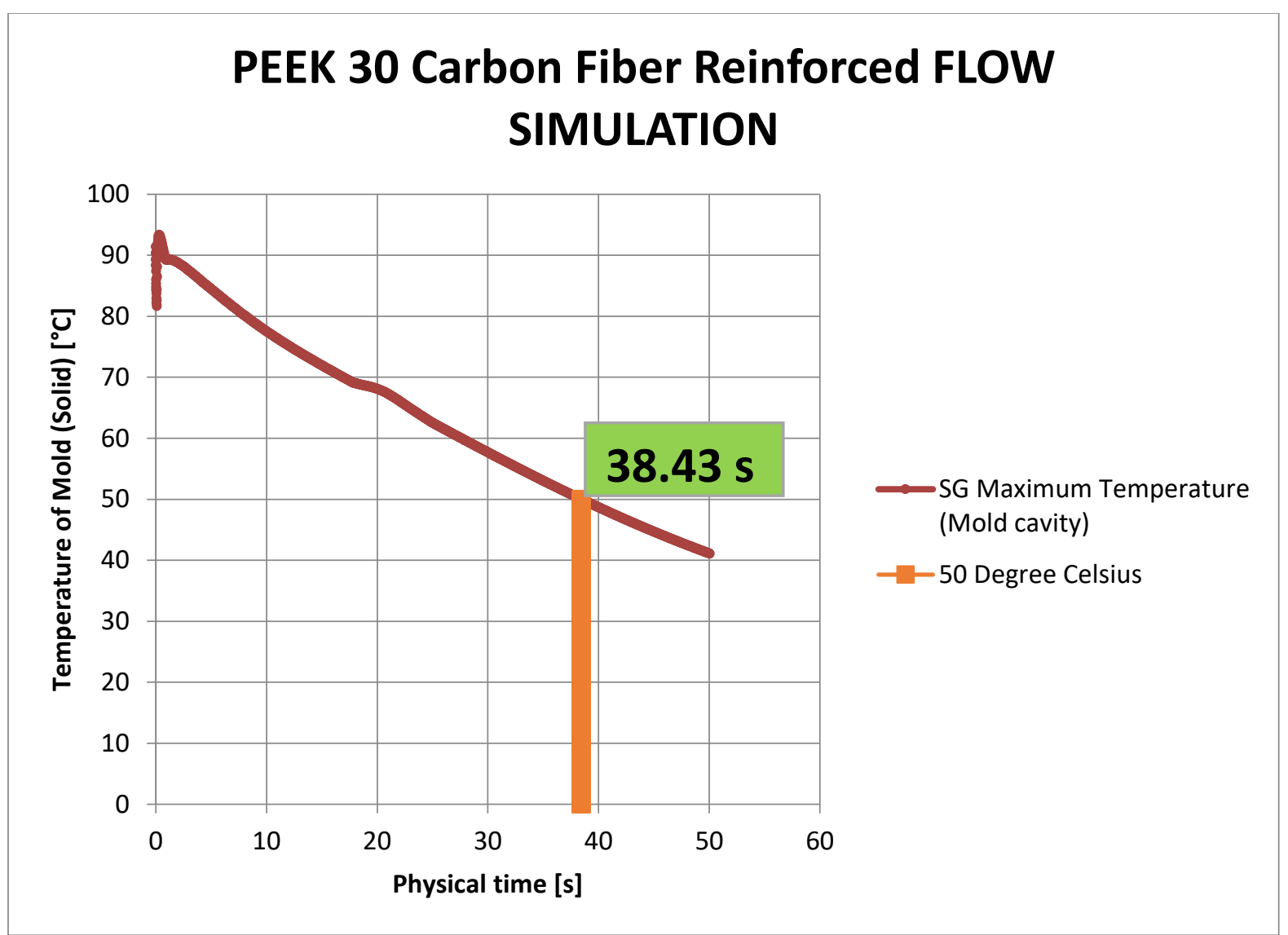

Figure 6 - A transient conjugate heat transfer cooling flow simulation on the injection mold cavity. The resulting time taken to cool the mold temperature to $50^{\circ} \mathrm{C}$ is 38.43 seconds with an inlet mass flow rate $=0.0005 \mathrm{~kg} / \mathrm{s}$.

In comparison to the results obtained from the transient thermal simulation $(29.1$ seconds for carbon reinforced PEEK), there is a cooldown time difference of 9.33 seconds. This difference is likely attributed to the early discussed issues associated with assuming that the temperature distribution of the hollow mold is uniform during cooling when a fluid is pumped through it. There is in fact a non-uniform temperature distribution that occurs from the initial point in which the water coolant is pumped in through the two inlets as shown in figure-7 below:

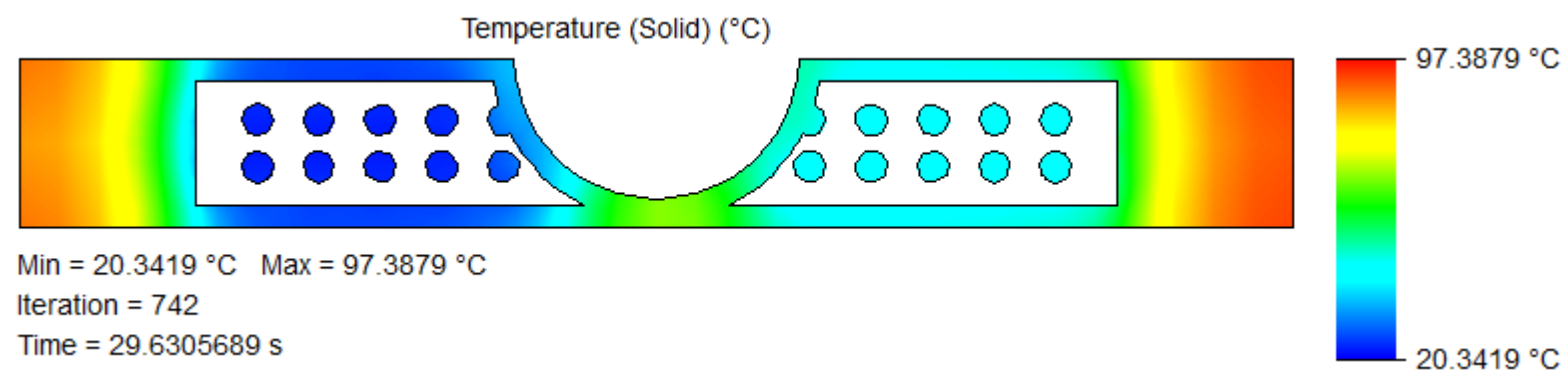

Figure 7 - A front plane cross-sectional view of the temperature distribution for the 3D Jacks Supports hollow model 742 iterations into the solving flow solution 


\section{Conclusion:}

In this simulation-based study, the implementation of hollow infill patterns was explored for its applications in making 3D printed polymer-based injection molds in additive manufacturing. The two main issues concerning 3D polymer-based molds that were addressed in this project involves the reduction of the time/cost it takes to manufacture (3D print) molds and the inherently slow heat transfer characteristics of polymer molds. Hollow infill structures are not only ideal for reducing the volume of material that needs to be printed (and thereby saving material costs without violating certain design stress and deformation constraints), but they are also viable for reducing the cooling time for polymer-based molds due to the implementation of certain design elements that allow for a coolant to be pumped in through the mold in a similar fashion to traditional conformal cooling channels.

From the preliminary hollow mold designs discussed earlier from a prior study conducted by Dr. Yasser Alizadeh and Dr. Faryar Etesami from the Mechanical \& Materials Engineering Department at Portland State University, the 3D Jacks Supports mold design was determined to be the best performer both in terms of material savings and its capacity to allow fluid coolant to flow through it. As such, this was the hollow infill pattern design that was ultimately implemented in this study and it's performance was compared to a base line solid mold pattern that serves to emulate a traditionally manufactured mold.

While the transient thermal analysis approach was initially expected to be sufficient in providing accurate results for the cooldown time due to the relatively small geometric dimensions of this particular HDPE lens mold, there were discrepancies between the results collected from these two simulation methods. As indicated by Figure-7, there is a distinctly noticeable nonuniformities in the temperature distribution of the mold as it is being cooled down. The left half of the mold in which the coolant first enters the hollow structure from the two inlets illustrate a much lower temperature near $20^{\circ} \mathrm{C}$ compared to the right half of the mold in which the coolant exits through the two outlets. This could be due to the obstruction of fluid flow as a result of the geometric density of the 3D Jacks supports along with the turbulent flow characteristics as the fluid enters and exits the hollow cavity. The result of this was that the real flow simulation yielded a cooldown time of 38.43 seconds compared to the transient thermal simulation which had a cooldown time of 29.1 seconds ( $27 \%$ difference).

Additional simulations would need to be performed in order to determine whether or not these non-uniform temperature distributions could be mitigated by adjusting the mass flow rate of the coolant fluid at the inlet (increasing the rate) without creating too great of an internal pressure within the mold. However, given that the external surfaces of the mold are constrained by mold carrier walls, it appears to be unlikely that this would become a significant issue. 


\section{References:}

[1] D. V. Rosato and M. G. Rosato, Injection molding handbook. Springer Science \& Business Media, 2012.

[2] Bryce, Douglas M. Plastic injection molding: manufacturing process fundamentals. Society of Manufacturing Engineers, 1996.

[3] E. Bassoli, A. Gatto, L. Iuliano, and M. G. Violante, "3D printing technique applied to rapid casting," Rapid Prototyping Journal, 2007.

[4] de Leon, Al C., et al. "High performance polymer nanocomposites for additive manufacturing applications." Reactive and Functional Polymers 103 (2016): 141-155.

[5] H. Shangguan, J. Kang, C. Deng, J. Yi, Y. Hu, and T. Huang, "3D-printed rib-enforced shell sand mold for aluminum castings," The International Journal of Advanced Manufacturing Technology, vol. 96, no. 5-8, pp. 2175-2182, 2018.

[6] Snelling, Dean A., Christopher B. Williams, and Alan P. Druschitz. "Mechanical and material properties of castings produced via 3D printed molds." Additive Manufacturing 27 (2019): 199-207.

[7] D. Snelling et al., "The effects of 3D printed molds on metal castings," in Proceedings of the Solid Freeform Fabrication Symposium, 2013, pp. 827-845.

[8] Dudescu, Cristian, and Laszlo Racz. "Effects of raster orientation, infill rate and infill pattern on the mechanical properties of $3 \mathrm{~d}$ printed materials." ACTA Universitatis Cibiniensis 69.1 (2017): 23-30. [

[9] E. Sachs, E. Wylonis, S. Allen, M. Cima, and H. Guo, "Production of injection molding tooling with conformal cooling channels using the three dimensional printing process," Polymer Engineering \& Science, vol. 40, no. 5, pp. 1232-1247, 2000, doi: 10.1002/pen.11251.

[10] D. E. Dimla, M. Camilotto, and F. Miani, "Design and optimisation of conformal cooling channels in injection moulding tools," Journal of Materials Processing Technology, vol. 164165, pp. 1294-1300, May 2005, doi: 10.1016/j.jmatprotec.2005.02.162.

[11] C.-C. Kuo, W.-H. Chen, J.-W. Zhang, D.-A. Tsai, Y.-L. Cao, and B.-Y. Juang, "A new method of manufacturing a rapid tooling with different cross-sectional cooling channels," Int $J$ Adv Manuf Technol, vol. 92, no. 9-12, pp. 3481-3487, Oct. 2017, doi: 10.1007/s00170-0170423-x.

[12] C. Deng, J. Kang, H. Shangguan, Y. Hu, T. Huang, and Z. Liu, "Effects of hollow structures in sand mold manufactured using 3D printing technology," Journal of Materials Processing Technology, vol. 255, pp. 516-523, May 2018, doi:

10.1016/j.jmatprotec.2017.12.031.

[13] Jahan, Suchana A., and Hazim El-Mounayri. "Optimal conformal cooling channels in 3D printed dies for plastic injection molding." Procedia Manufacturing 5 (2016): 888-900. 
[14] "Overview of materials for Polyetheretherketone, Unreinforced." http://www.matweb.com/search/DataSheet.aspx?MatGUID=2164cacabcde4391a596640d553b2e be (accessed Mar. 14, 2020).

[15] J. Li and L. Q. Zhang, "Reinforcing effect of carbon nanotubes on PEEK composite filled with carbon fibre," Materials Science and Technology, vol. 27, no. 1, pp. 252-256, 2011, doi: 10.1179/174328409X453226.

[16] J. Li and L. Q. Zhang, "The research on the mechanical and tribological properties of carbon fiber and carbon nanotube-filled PEEK composite," Polymer Composites, vol. 31, no. 8, pp. 1315-1320, 2010, doi: 10.1002/pc.20916.

[17] N. Mahmoudi, "IMPROVEMENT OF MECHANICAL AND TRIBOLOGICAL PROPERTIES OF CARBON FIBER REINFORCED PEEK COMPOSITE FILLED WITH CARBON NANOTUBES," Annales De Chimie-Science Des Materiaux, vol. 39, no. 1-2, pp. 110, 2015, doi: 10.3166/acsm.39.1-10. 